\title{
PEMBAKUAN AKTIVITAS PERGUDANGAN DENGAN STANDARD OPERATING PROCEDURE (SOP) DI PT. XYZ
}

ISSN 1411 - 5247

\section{Erwin Sitorus $^{1}$,Siti Soraya Faiza Nasution ${ }^{2}$}

\begin{abstract}
In realizing professional, effective, and efficient work, as well as improvement of work system, the company requires Standard Operating Procedures (SOP). SOP is a guide or reference to perform job tasks in accordance with the function and also a tool of performance appraisal company based on technical, administrative, and procedural indicators in accordance with work procedures and work system in the work unit concerned. Problems that occurred at PT. XYZ is the absence of standardization and documentation of work standards for warehousing activities resulting in non-standard work quality. The purpose of this research is to arrange Standard Operating Procedure (SOP) based on work elements in each warehousing activities in warehouse of PT. XYZ. The result of the research is the preparation of SOP for the acceptance of coffee beans, the storage of coffee beans, the delivery of coffee beans to the production, and the delivery of coffee to the consumers.
\end{abstract}

Keywords : SOP, warehousing, coffee beans, procedure

\footnotetext{
${ }^{1}$ Departemen Teknik Industri, Fakultas Teknik, Universitas Sumatera Utara Jl. Almamater Kampus USU, Medan 20155 email : erwin_birosdmusu@yahoo.com

2 Departemen Teknik Industri, Fakultas Teknik, Universitas Sumatera Utara Jl. Almamater Kampus USU, Medan 20155 email : sitisorayafaizanst@gmail.com
} 
1. Pendahuluan

Suksesnya suatu kegiatan di dalam perusahaan berkaitan dengan peningkatan produktivitas kerja. Upaya untuk meningkatkan produktivitas kerja berkaitan dengan kegiatan perbaikan sistem kerja yang ada, dimana sistem kerja tersebut meliputi beberapa faktor yaitu manusia, bahan, metode, perlengkapan, dan peralatan. Salah satu faktor yang menyebabkan menurunnya sistem kerja yaitu ditemukannya kondisi dalam perusahaan yang tidak sesuai dengan prosedur yang berlaku. Terlebih pada pekerjaan real di lapangan yang sering juga didapati bahwa terdapat prosedur yang tidak dipatuhi.

Dalam mewujudkan pekerjaan yang profesional, efektif dan efisien, serta peningkatan sistem kerja, perusahaan membutuhkan suatu prosedur operasi standar atau yang lazim disebut Standard Operating Procedures (SOP). SOP adalah pedoman yang berisi prosedur-prosedur operasional standar yang ada di dalam suatu organisasi yang digunakan untuk memastikan bahwa setiap keputusan, langkah, atau tindakan, dan penggunaan fasilitas pemrosesan yang dilaksanakan oleh orang-orang di dalam suatu organisasi telah berjalan secara efektif, konsisten, standar, dan sistematis.

PT. XYZ merupakan sebuah perusahaan yang bergerak dalam bidang manufaktur pembuatan kopi kemasan. Gudang di PT. XYZ belum mempunyai Standard Operating Procedure (SOP) yang baku sehingga masih banyak aktivitas yang dilakukan belum sesuai prosedur yang standar dan juga tidak ada penanggung jawab dari setiap aktivitas yang dilakukan.

Tujuan dari penelitian ini adalah menyusun Standard Operating Procedure (SOP) berdasarkan elemen pekerjaan dalam tiap aktivitas pergudangan di Gudang PT. XYZ.

\section{Metode Penelitian}

Jenis penelitian yang dilakukan adalah penelitian deskriptif. Jenis penelitian ini mendeskripsikan secara sistematik, faktual, dan akurat tentang fakta-fakta dan sifat-sifat suatu objek tertentu.
Metode pengumpulan data dan informasi yang digunakan pada penelitian ini adalah yaitu observasi dan wawancara.

Sistematika penelitian dapat dilihat pada Gambar di bawah ini.

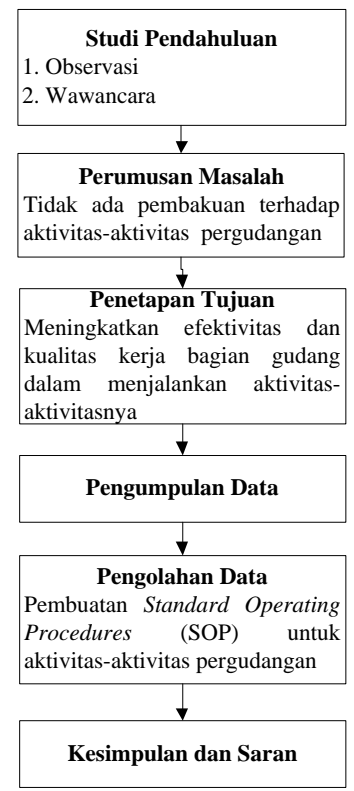

Gambar 1. Sistematika Penelitian

\section{Pembahasan}

3.1. Penyusunan Standard Operating Procedure (SOP) Penerimaan Biji Kopi

Rincian aktivitas penerimaan biji kopi di

PT. XYZ adalah sebagai berikut:

1. Petugas gudang memeriksa kelengkapan dan keabsahan Surat Pemberitahuan Penerimaan Barang (SPPB).

2. Petugas gudang memeriksa jumlah dan kualitas barang yang diterima sesuai dengan dokumen pengiriman dengan bagian Quality Control.

3. Jika jumlah dan spesifikasi barang sesuai dengan SPPB, petugas gudang membubuhkan tanda tangan dan nama jelas, stempel perusahaan, dan tanggal penerima pada SPPB serta meminta tanda tangan Kepala Bagian Tata Usaha (KTU).

4. Petugas gudang menempatkan barang ke tempat yang telah ditentukan dalam gudang, dan tidak bisa langsung dicampur dengan stok lama sebelum dilakukan perhitungan ulang dan update stock card.

5. Petugas gudang mencatat jumlah penerimaan ke dalam stock card 
berdasarkan jumlah yang benar-benar diterima.

6. Petugas gudang membuat Berita Acara Penerimaan Barang (BAPB) dan meminta tanda tangan pihak terkait.
7. Petugas gudang mendistribusikan BAPB sesuai dengan daftar distribusi yang telah ditentukan.

SOP penerimaan biji kopi di Gudang PT. XYZ ditampilkan pada tabel di bawah ini.

Tabel 1. Standard Operating Procedure (SOP) Penerimaan Biji Kopi

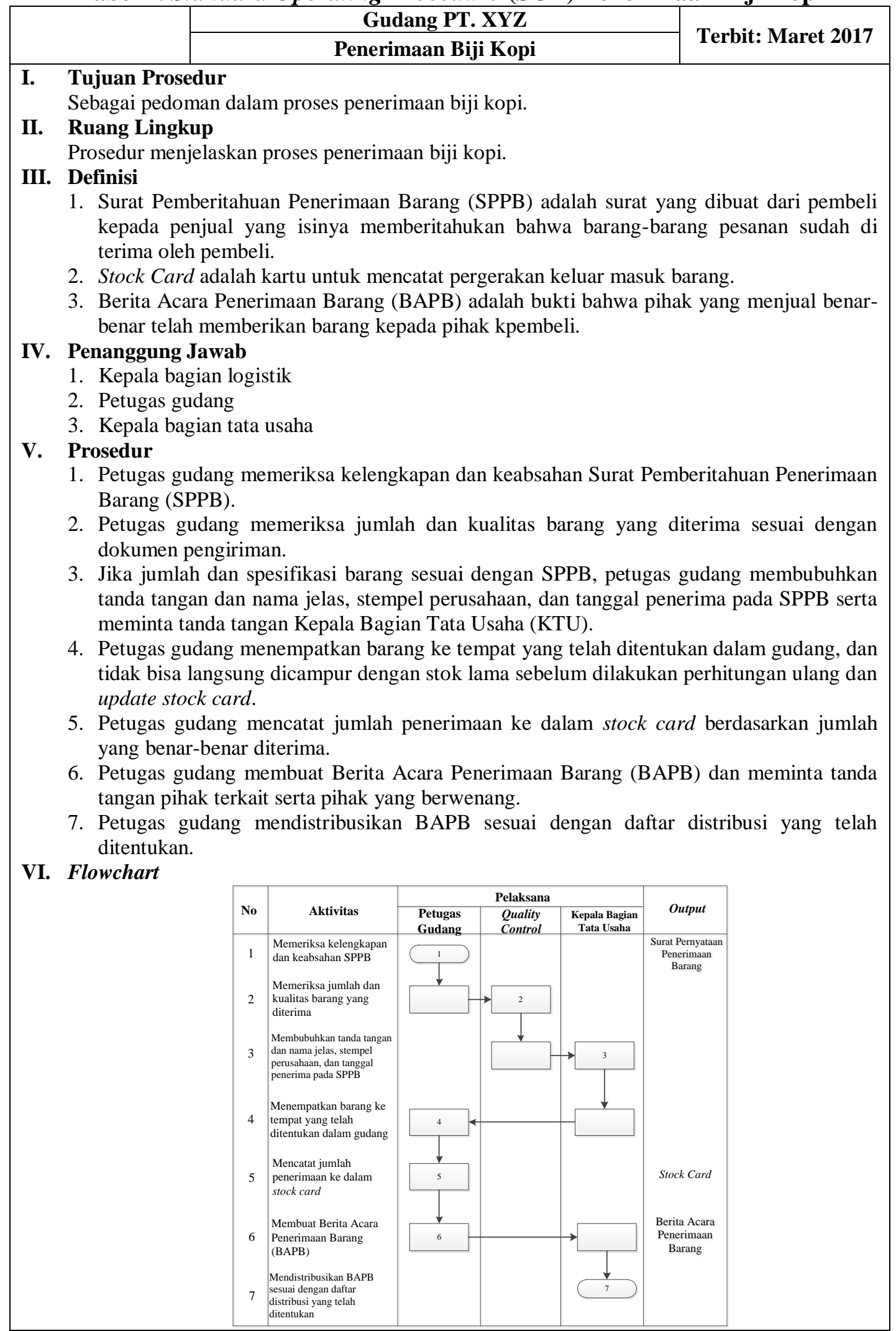




\subsection{Penyusunan Standard Operating Procedure (SOP) Penyimpanan Biji Kopi}

Rincian aktivitas penyimpanan biji kopi di Gudang PT. XYZ adalah sebagai berikut:

1. Petugas gudang mengidentifikasi karakteristik produk untuk menentukan produk diletakkan di kelompok produk sejenis.

2. Petugas gudang mencari tempat untuk penyimpanan barang.

Tabel 2. Standard Operating Procedure (SOP) Penyimpanan Biji Kopi

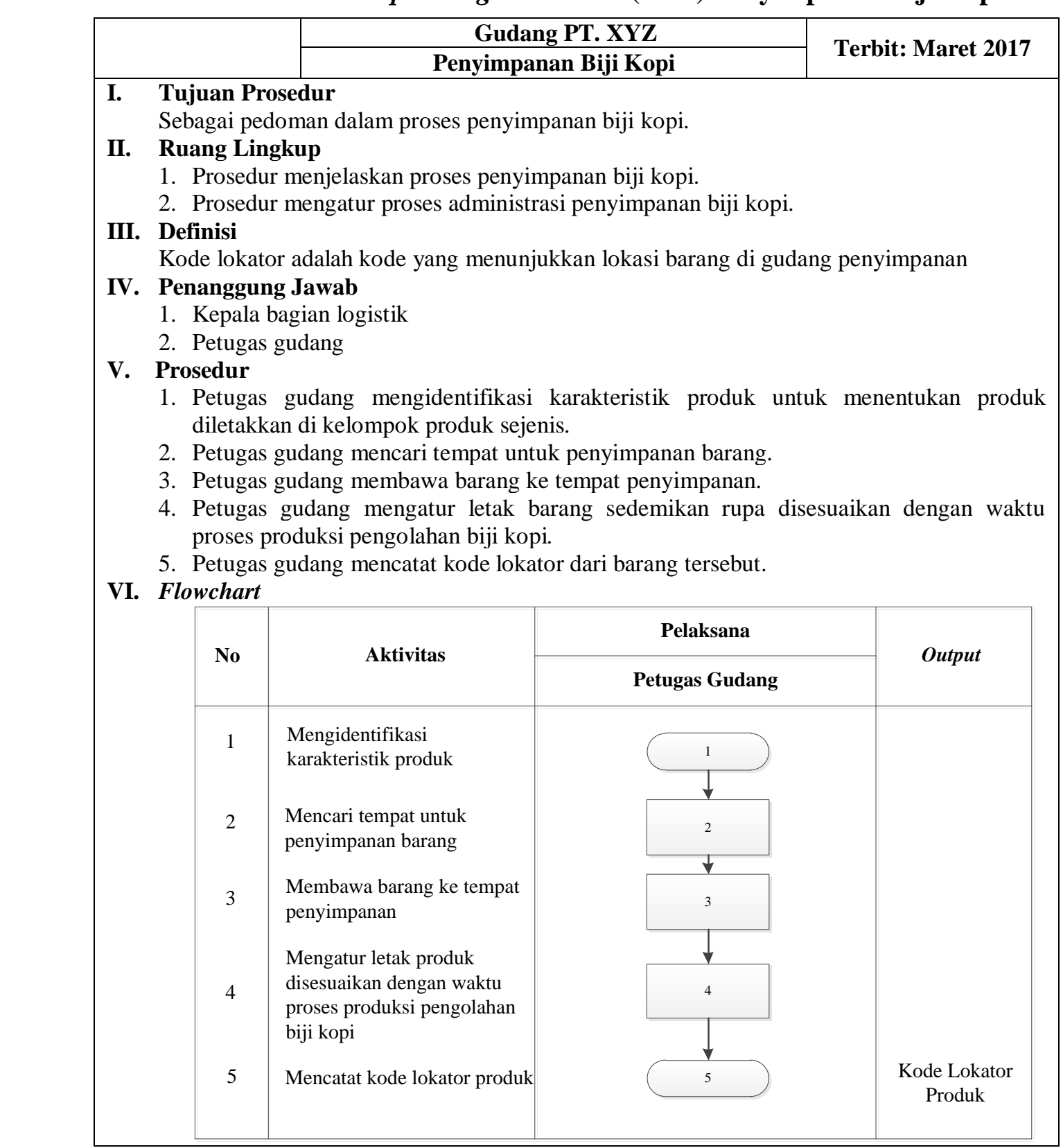

3. Petugas gudang membawa barang ke tempat penyimpanan.

4. Petugas gudang mengatur letak barang sedemikan rupa disesuaikan dengan waktu proses produksi pengolahan biji kopi.

5. Petugas gudang mencatat kode lokator dari produk tersebut.

SOP penyimpanan biji kopi di Gudang PT. XYZ ditampilkan pada tabel di bawah ini. 


\subsection{Penyusunan Standard Operating Procedure (SOP) Pengiriman Kopi ke Konsumen}

Rincian aktivitas pengiriman kopi ke konsumen di Gudang PT. XYZ adalah sebagai berikut:

1. Petugas gudang menerima Purchase Order (PO) dari bagian penjualan.

2. Petugas gudang mengecek ketersediaan stok barang yang dibutuhkan.

3. Petugas gudang mengeluarkan Sales Order (SO), SO dibuat 3 rangkap:

a. Bagian gudang

b. Bagian finance (sebagai dasar pembuatan Invoice)

c. Bagian customer

4. SO diberikan ke bagian logistik sebagai dasar untuk mempersiapkan produk.

5. Bagian logistik menginput data pengeluaran produk.
6. Bagian logistik mengeluarkan Delivery Order (DO), DO dibuat 4 rangkap:
a. Bagian gudang
b. Bagian customer
c. Bagian accounting
d. Bagian finance

7. Petugas gudang mengeluarkan produk.

8. Petugas gudang melakukan pengecekan produk.

9. Bagian logistik membuat jadwal pengiriman produk.

10. Produk diserahkan ke bagian staff pengiriman untuk dikirim ke customer.

11. Setelah barang diterima customer dan dilakukan pengecekan barang, maka DO diberikan ke bagian logistik sebagai tanda bahwa customer telah menerima produk.

SOP pengiriman kopi ke konsumen di Gudang PT. XYZ ditampilkan pada tabel di bawah ini.

Tabel 4. Standard Operating Procedure (SOP) Pengiriman Kopi ke Konsumen

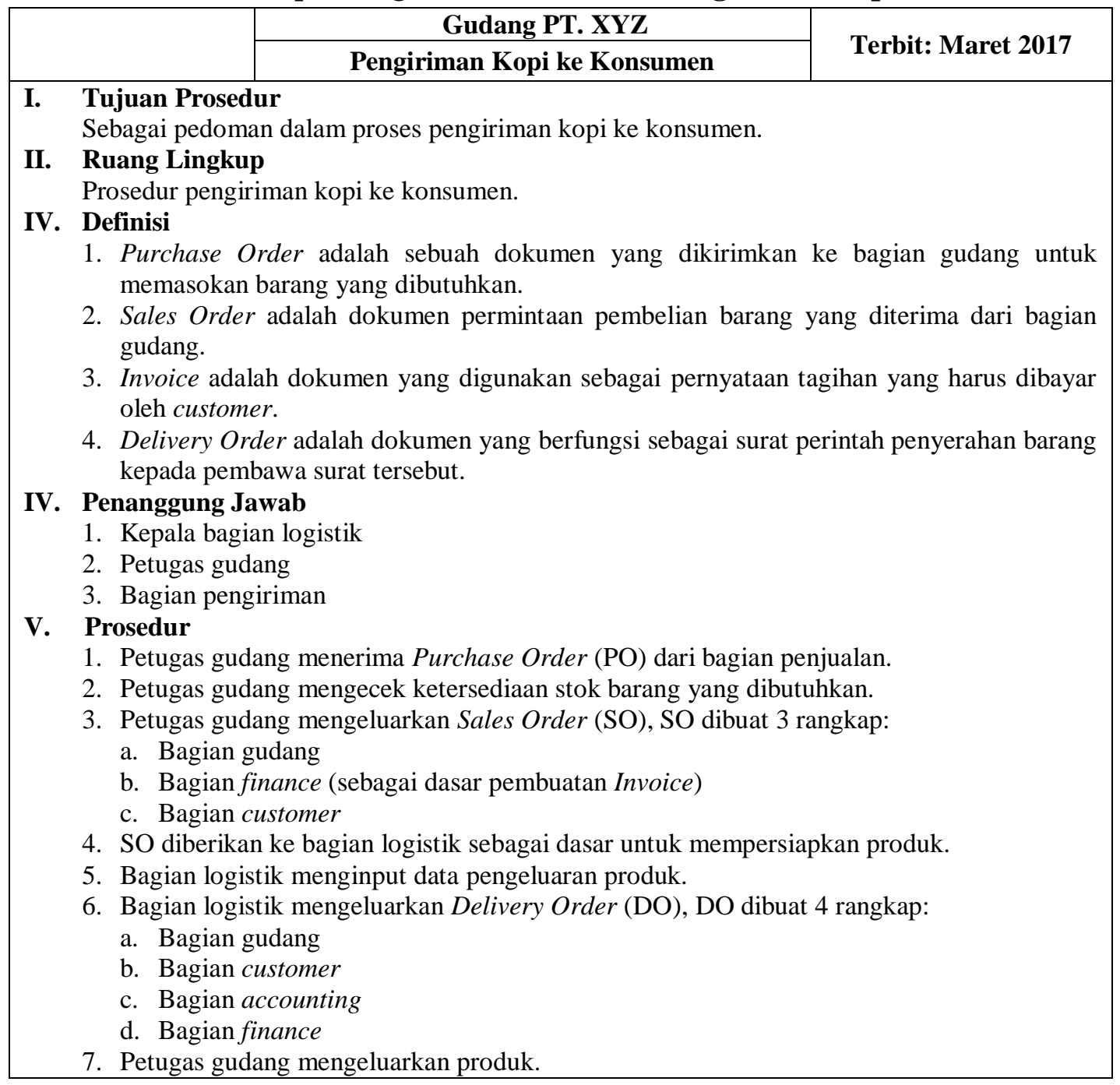




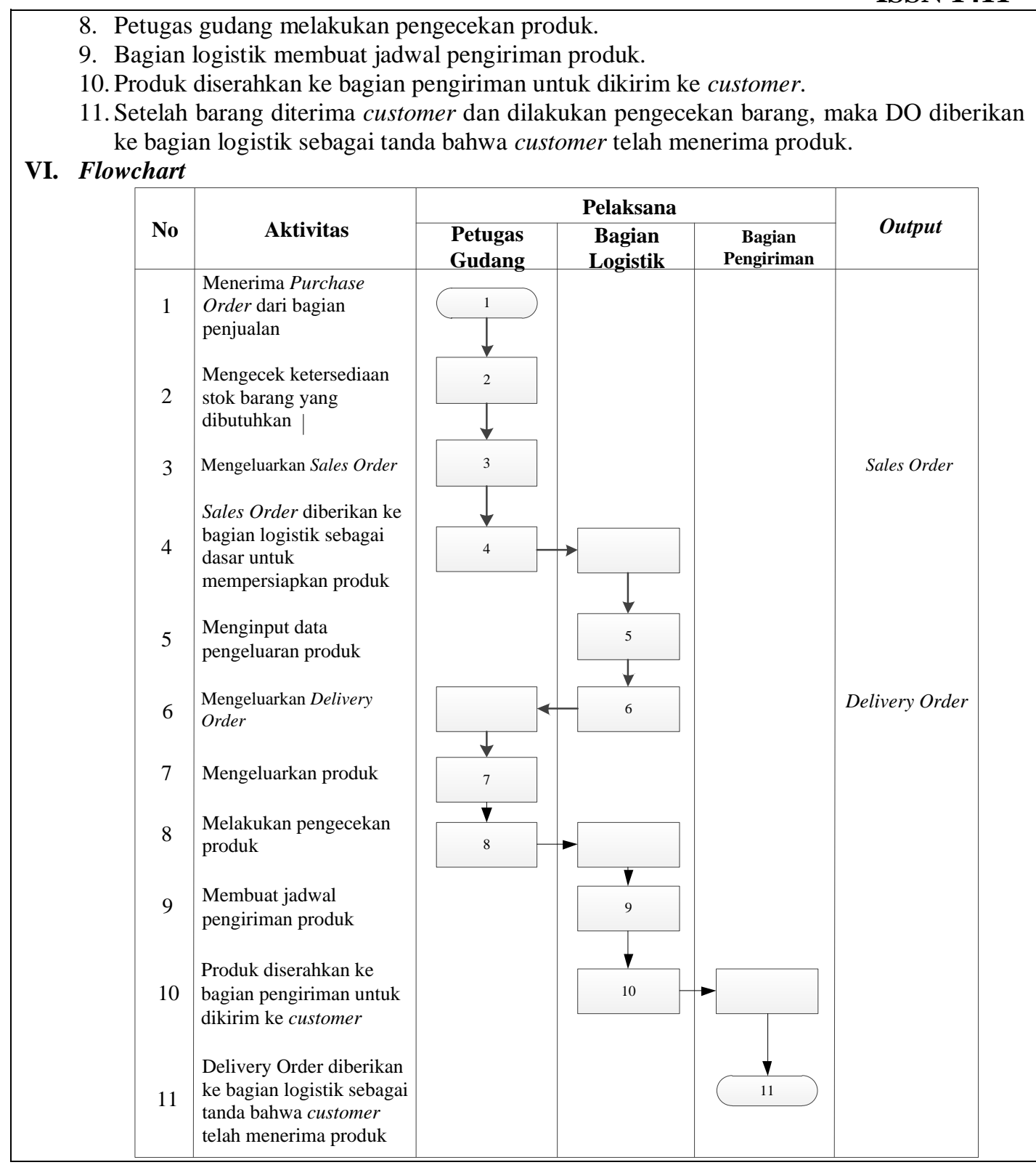

\section{Kesimpulan}

Kesimpulan yang dapat ditarik dari pengamatan pada aktivitas gudang di PT. XYZ yaitu Standard Operating Procedure (SOP) untuk aktivitas pergudangan belum dibakukan dan didokumentasikan sehingga dilakukan penyusunan Standard Operating Procedure (SOP) berdasarkan elemen pekerjaan dalam tiap aktivitas pergudangan di Gudang PT. XYZ meliputi penerimaan biji kopi, penyimpanan biji kopi, pengiriman biji kopi ke bagian produksi, dan pengiriman kopi ke konsumen.
Ekotama, Suryono, (2011), Cara Gampang Bikin Standard Operating Procedures, Media Presindo, Jakarta

Susila, Nyoman, (1983), Pemrograman Komputer Fortran IV, Cipta Karsa, Bandung

Sutalaksana, I.Z., (2006), Teknik Perancangan Sistem Kerja, Penerbit ITB, Bandung

Tambunan, R.M., (2008), Standard Operating Procedures, Maiestas Publishing, Jakarta

\section{Daftar Pustaka}

